\title{
Providing Health Information for Patients, Families and the Public
}

\author{
Joyce E.B. BACKUS ${ }^{\mathrm{a}, 1}$ and Eve-Marie LACROIX ${ }^{\mathrm{a}}$ \\ ${ }^{a}$ U.S. National Library of Medicine (retired)
}

\begin{abstract}
When Dr. Lindberg was sworn in as Director, the National Library of Medicine (NLM) was providing few resources with information useful to the public, having concentrated efforts towards health professionals and scientists. With his arrival, and that of the Internet in the 1990s, NLM embarked on a research and userfocused path towards providing authoritative health information for patients, families and the public. MedlinePlus, NIHSeniorHealth, and MedlinePlus en espanol delivered health information in a variety of formats using text, still images, audio and video. These resources were supported by NLM advisors and Dr. Lindberg's strong belief that patients and families needed easy access to medical information to be able to effectively care for themselves in illness and maintain the best health possible throughout their lives.
\end{abstract}

Keywords. MedlinePlus, Consumer Health Information, MedlinePlus en español, Go Local, NIHSeniorHealth, MedlinePlus Connect, U.S. National Library of Medicine, Donald A. B. Lindberg M.D.

\section{Introduction}

When Donald A.B. Lindberg MD became the Director of the National Library of Medicine (NLM) in 1984, the Library was focusing its collections on publications for biomedical scientists and health professionals, not patients and families. Under Dr. Lindberg's leadership, NLM created and expanded resources for patients and nonprofessionals, most notably MedlinePlus, MedlinePlus en español, and NIHSeniorHealth. He insisted that these services connect to other NLM resources, especially ClinicalTrials.gov and PubMed. These new services supported his belief that patients and their families need authoritative and accurate information so they focused on information from the government and other authoritative sources. He also strongly supported multimedia resources for consumers, hence agreements for the encyclopedia with images, videos of surgeries conducted at U.S. university medical centers, and illustrated tutorials with audio narration. He initiated a partnership with the National Institute on Aging to create NIHSeniorHealth - including greater accessibility for seniors with features like text resizing and text to speech. As not everyone in for-profit organizations or in government supported this direction for NLM, Dr. Lindberg's leadership was instrumental, as was the support of key members of NLM's long range planning committees and Board of Regents.

1 Joyce E.B. Backus, 1301 Bellenden Drive, Durham, NC 27713, USA; E-mail: joycebackus@alumni.duke.edu 


\section{Dr. Lindberg, Community Input, and Early MedlinePlus}

In his 1984 swearing in address, Dr. Lindberg emphasized the growing importance of computerized information: "For the practitioner of medicine, the book or journal on the shelf will become increasingly too remote for immediate patient care decisions, and the computer-based personal information station will become increasingly useful, comforting, perhaps essential" [1]. During the next decades, his words became true, not only for medical practitioners, but for all members of society. Computers became more personal, local and handheld. As he led NLM towards this vision of computerized information on personal stations, Dr. Lindberg engaged experts through strategic planning panels and the NLM Board of Regents, to provide direction, advice and guidance. He also supported research-based development that guided the initial pilot, release, implementation and improvement of MedlinePlus and related services.

\subsection{User Centered Development}

Under Dr. Lindberg's leadership, the Library decided to provide MEDLINE free on the Internet in 1997. Providing MEDLINE free to anyone with an Internet connection and a Web browser revealed an appetite for medical information from the general public. After one-year, one-third of PubMed interactions were likely by consumers, not biomedical professionals, although MEDLINE citations and abstracts are not ideal consumer health information sources [2]. With evidence of information seeking by the public, NLM considered how it might effectively meet their information needs in the Internet age. An important research project to determine the answer was a pilot with 40 public library systems, coordinated by NLM's National Network Office. This pilot project, in cooperation with National Network of Libraries of Medicine (NN/LM), the Friends of the NLM, the Kellogg Foundation, the Medical Library Association, and the Public Library Association, gathered feedback on what content and structure would be helpful for libraries to provide health information to their communities. Early MedlinePlus provided these libraries with a resource they could test to see how it fit the needs of their patrons.

The pilot project revealed that health information is always among the top types of information public library patrons request. It also revealed that these patrons would benefit from an easy to use, authoritative, health information service through the Internet [3]. When NLM released MedlinePlus in October of 1998, the website leveraged institutional strengths and Dr. Lindberg's vision of the future [4]. The close partnership of the content and process experts in the Division of Library Operations and the information technology talent of the Office of Computer and Communications Services resulted in a strong initial web site, both in content and structure.

\subsection{Board of Regents Policy, Planning Panel, and Public Library Advice}

Dr. Lindberg furthered the library's successes through the advice of community leaders. In 1999, the Library's Board of Regents approved a new policy, "NLM and Health Information for the Public." As they had discussed in several preceding meetings, this policy called upon the Library to: 
Organize selected authoritative electronic information that is available at low or no-cost, with an emphasis on science-based, nationally applicable resources.

Develop easy-to-use access and delivery mechanisms that promote the public's understanding of health information, drawing on research in lay terminology, graphical and multimedia presentation, etc.

Publicize reputable electronic health information services, including those available from NLM and other sources.

Assist those providing health information to the public to make effective use of electronic services through Internet connections, training, and other means, with an emphasis on those serving minority groups, low income populations, seniors.

Promote integration of NLM services with other electronic services covering regional, state, or local health information [5, Attachment 1].

Building on and amplifying the Board's new policy, the planning panels that Dr. Lindberg convened also addressed consumer information. Specific advice regarding information for patients and the public was included in the "NLM Long Range Plan 2000-2005," which stated:

NLM has historically focused its services and products on an audience of health professionals and biomedical scientists. ...NLM has a responsibility to develop technologies and information systems that meet the public's interest in accurate current, and understandable health information. NLM should partner with federal agencies, voluntary health organizations and others to identify gaps, arrange for development of understandable content, and help the public make effective use of electronic health information [6].

The public library pilot and expert recommendations reconfirmed that the authority and source of health information is very important for patients and the public. From the outset, NLM created selection criteria for resources included in MedlinePlus. Experienced medical librarians at NLM and other medical libraries applied their expertise in evaluating biomedical information resources to create selection guidelines for MedlinePlus. With the proliferation of health information on the internet from organizations, both profit-making corporations and nonprofit educational organizations, it was vitally important to implement guidelines so that MedlinePlus would be a trusted source of health information and the content guidelines continue to be an important part of MedlinePlus to this day [7].

\subsection{Research and Operations Collaboration}

When MedlinePlus was released in late 1998 with just over 20 topics, they were based on actual user searches of NLM web sites. This collaboration fulfilled Dr. Lindberg's desire that NLM research inform its services. The process was described in this early paper:

Staff of NLM's Lister Hill National Center for Biomedical Communication (LHC) performed mapping and analysis on a five-week sample of searches. The 
search $\log$ contained 87,423 searches that the LHC staff mapped to 56,905 concept terms using the Unified Medical Language System (UMLS), Metathesaurus, SPECIALIST Lexicon, and lexical programs. Of these, over 8,446 occurred more than once and 2,676 could be mapped directly to NLM's Medical Subject Headings known as MeSH terms. For example, shingles, zoster, and herpes zoster were mapped to herpes zoster; herniated disk and slipped disk were mapped to intervertebral disk displacement.

Once mapped, the terms were ranked by search frequency. The most frequently searched topics included diabetes, shingles, prostate, hypertension, asthma, lupus, fibromyalgia, multiple sclerosis, cancer, and other diseases. Drug topics such as Viagra and Zoloft, and alternative medicines such as St. John's Wort were also frequently searched. A target health topic list of more than 300 was developed based on the analysis of user searches to ensure that the health topics of interest to users were included in MEDLINEplus [8].

This research-based and user-centered process to identify and prioritize the health topics reflected Dr. Lindberg's priorities. He wanted the NLM program divisions, such as Library Operations and the Office of Computer and Communications Systems (OCCS) to collaborate with, and benefit from, the experts in the LHC research Division. This collaboration to identify and prioritize MedlinePlus topics brought together the research expertise of the LHC team and the informatics tools they had created, especially the UMLS, with the staff of operational divisions in the creation and development of MedlinePlus.

\subsection{Connecting Users to NLM Information}

Dr. Lindberg wanted users of MedlinePlus to be able to find other NLM resources. Staff investigations showed that information seekers want basic overviews at the beginning of their health information journey. Some patients and families develop a deeper understanding of a health condition, because of its serious nature or because it is a longterm chronic condition. Such lay experts have mastered the medical terminology and basic concepts and want to explore the latest scientific research. To serve these patient and family "experts," MedlinePlus provided custom searches from each health topic linking directly to MEDLINE/PubMed. These links were important to connect people to the scientific literature.

When ClinicalTrials.gov was launched in February, 2000, MedlinePlus linked to that important new resource. Once at the clinical trials site, patients and their families and physicians could browse the list of trials, view the inclusion criteria for participants, and decide if they wished to consider participation in a clinical trial. The ClinicalTrials website also linked back to MedlinePlus "to help place clinical trials in the context of a patient's overall medical care" [9, p.36]. These connections fulfilled Dr. Lindberg's desire that NLM services not exist in isolation but connect people to the richness of NLM resources available whenever they wished to pursue them. [10] 


\section{Dr. Lindberg's Influences as MedlinePlus Evolves and Adds Spanish, Illustrated Encyclopedia and Talking Tutorials}

As more people used MedlinePlus, they sent comments, questions and suggestions. To supplement this feedback, staff used new web analytics techniques and tools to gather feedback which drove improvements. Staff conducted some of the first usability tests done at NIH, in partnership with the University of Maryland Human Computer Interaction Lab of Ben Schneiderman. They analyzed search and web use logs. NLM was one of the first government organizations to implement the American Customer Satisfaction Index (ACSI) and the respondents consistently ranked MedlinePlus as one of the top government information websites, bringing it attention from the Wall Street Journal [11], Consumers Reports [12], and others.

\subsection{Forming the NIH MedlinePlus Advisory Group}

Dr. Lindberg's desire that NLM work closely with government partners supported the creation of an NIH MedlinePlus Advisory Group. This group, composed of representatives from the communications offices or information clearinghouses of other NIH Institutes, facilitated regular NIH feedback and cooperation. This group became an important forum for NLM to communicate the value of MedlinePlus, and show that it improved the ability of the public to find relevant information. Through the members, NLM provided other NIH Institutes with data showing the volume of web traffic NLM directed to their sites. For many years, the Advisory Group provided a regular forum for communication and cooperation, not just with NLM, but among the leaders of public outreach offices of other NIH Institutes [13].

\subsection{Growing MedlinePlus with More Topics, Images and Talking Tutorials}

When it launched in October of 1998, MedlinePlus provided just 22 topics to serve as the public library pilot, to sense the appetite for such a service, and to gauge the level of effort and funding needed for NLM to grow and sustain an NLM quality service. With the MedlinePlus topic model established and piloted, the most frequent request was for more topics, and the staff worked quickly to meet this user demand. By the end of 1998, there were 44 health topics, and 212 just a year later. By 2000, it provided over 400 health topics and nearly 400,000 unique users viewed over 3 million MedlinePlus pages [14]. NLM had listened to advisors and users in working towards Dr. Lindberg's goal of delivering a respected source of information for patients and their families and friends.

Staff recognized that there were gaps in the information provided by the NIH and other government and authoritative nonprofit sources that MedlinePlus depended upon. They identified these gaps from zero-hit searches, health questions sent to NLM, and requests for additions. Information gaps were especially noticeable in the areas of drug information, symptoms, anatomy, and medical procedures. With Dr. Lindberg's support, MedlinePlus added a patient drug information resource from the US Pharmacopeia and an illustrated encyclopedia of over 4000 articles from A.D.A.M. [9,p.vi]. The illustrated encyclopedia was of particular interest to Dr. Lindberg because of his understanding of how important pictures can be in improving one's understanding of a health problem.

Because he knew Dr. Lindberg was seeking ways to improve patient understanding, Steve Philips M.D. made him aware of talking health tutorials from an organization in Iowa called the Patient Education Institute. These tutorials used simplified language, 
included illustrations throughout, and also incorporated a talking feature. Dr. Lindberg recognized that these titles could be an important addition to MedlinePlus and one not likely to be available from another government or non-profit source. The talking feature was especially valued by patients because the audio clearly pronounced medical terms they could see on the screen and repeat as needed. MedlinePlus released the first 30 of these talking tutorials in 2001, and eventually provided 200 of them [15]. They were part of MedlinePlus for many years until the technology used for the talking animations was no longer easily supported.

\subsection{MedlinePlus Delivers in Spanish}

One of the major enhancements to the MedlinePlus program was to create a Spanishlanguage version. Dr. Lindberg strongly supported this enhancement, noting the success of the Spanish language offerings from NOAH, the New York Online Access to Health program when bringing it to the Board's attention in their May 1999 meeting [16].

"There was a discussion of the need for more consumer health information in Spanish, and Dr. Lindberg described "NOAH," a volunteer effort of librarians in New York City to point to sources of medical information for consumers and link to New York resources. NOAH translates information from NIH Institutes into Spanish. NLM's MedlinePlus points to NOAH in a number of places" [5].

MedlinePlus en espanol was also supported by the panel experts who recommended in "NLM Long Range Plan 2000-2005," "Develop easy-to-use access and delivery mechanisms that promote the public's understanding of health information resources. These should be sensitive to cultural diversity issues, educational level, and language (e.g., Spanish)."

Following these recommendations, NLM developed and released a complete Spanish language version of MedlinePlus in 2002. MedlinePlus en espanol was a fullfledged web site that included 500 health topics with links to many government resources, drug information, and an illustrated medical encyclopedia in Spanish [17]. NLM leveraged lessons learned from years of feedback on the English-language site, incorporated them into this new Spanish language site, and hired staff who could maintain the same high standards of selectivity and authority in Spanish. One important function was that the English and Spanish sites crosslinked as completely as possible so that physicians, family members and others could navigate and read in the language of their choice, and easily toggle to the other language. From day one, Dr. Lindberg supported the Spanish language site to grow in parallel with the English site, and it expanded with most of the additions afforded the English language site over the years.

\section{Meeting Additional Needs: Images, Seniors, Local Health Services, Electronic Health Records}

Following the success of MedlinePlus and MedlinePlus en espanol, consumer health information services from NLM continued to expand and were strongly supported by Dr. Lindberg and the long range planning and Board of Regents advisory groups. In growing the program, NLM added more images, collaborated with the U.S. National Institute on Aging (NIA) and other Institutes to create NIHSeniorHealth.gov, with libraries around 
the country to create Go Local, and with health systems and electronic health record (EHR) developers to connect health information to patient portals.

\subsection{Adding More Moving and Still Images}

Because of the success of MedlinePlus and the excellent reputation of NLM, there were many offers of content, partnerships, and connections from organizations with a variety of products and motivations. Some inquiries wanted the NLM "endorsement," some wanted to increase awareness of their products, some were looking for government funding, and some wanted all of these outcomes. The staff responsible for MedlinePlus reviewed these inquiries to see if any furthered the NLM goals of providing understandable and authoritative health information to the public in a variety of ways, as stated in the Strategic Plan Addressing Health Disparities 2004-2008, "Objective 3.1.1 Improve delivery of health information, through the development of easy-to-use information resources such as MedlinePlus that are sensitive to cultural diversity issues, educational level, and language." [18]

One such partnership that Dr. Lindberg reviewed and supported was to provide videos of recorded live surgeries. While not a top request like the drug information already provided on MedlinePlus, there was evidence that some people would want to watch videos of actual surgeries. Dr. Lindberg, willing to give these a try after meeting with the principals at OR-Live.com in 2004, agreed they were a unique new way to provide information to the public. While they were never the most-used resource on MedlinePlus, a pilot proved that some people were interested and found the surgery videos very helpful. After staff worked with the company to agree to supply only videos from Accredited Academic Medical Centers and provide closed captioning in English and Spanish, MedlinePlus eventually provided access to dozens of surgery procedures. Patients who wanted it, now had an audiovisual experience to better understand an upcoming or recent procedure.

In another partnership Dr. Lindberg supported the idea of providing images of dermatological conditions from an organization called VisualDx. This organization had obtained a unique collection of skin condition images from reliable medical school sources with good accompanying descriptions. After meeting with founder Art Papier M.D., Dr. Lindberg supported providing these images as an enhancement to textual information to increase understanding about skin problems. In 2007 MedlinePlus added links to this unique content featuring high quality dermatology images and information on over 150 diseases and conditions. MedlinePlus links to the consumer successor, SkinSight today, in this continued partnership [19].

\subsection{NIH Partnership to Serve Older Americans}

NIHSeniorHealth was a consumer health service that Dr. Lindberg initiated as a partnership with the U.S. National Institute on Aging (NIA). He discussed the need for health information delivered in a way that resonated with older adults with the Director of NIA, Richard Hodes M.D. They agreed to bring the strengths of each of their organizations together to lead NIH in creating a new kind of website. NLM brought expertise in creating systems and processes to deliver health information effectively and use evolving web measurement techniques to improve them. NIA had strengths in creating information for older people, geared to their specific needs. 
NIHSeniorHealth officially launched in October of 2003 on Capitol Hill at a public briefing requested by Senator Tom Harkin of Iowa. The website included many innovations for seniors to facilitate learning about health even as cognition, vision or hearing might be in decline, that were heralded by Drs. Lindberg and Hodes [20]. Staff of NIA and NLM used research on how seniors best gained information from computers and performed live testing with seniors on the prototypes before releasing the website. Dr. Lindberg welcomed feedback from former NLM director, Martin Cummings M.D. and his computer users club of seniors in Florida who tested and provided suggestions for improvement.

NIHSeniorHealth was innovative in many ways. With a click of a button, it would talk and read aloud the text on the page. The text itself was written in the easiest language possible to convey the correct health information. If users needed a larger font, they could use buttons to choose a large, larger or largest font. People could also choose white or yellow text on a dark background, a contrast that improves readability for some vision problems. It was a realization of Dr. Lindberg's view that NLM needed to deliver health information in a variety of ways and did so for the next 14 years.

In 2017, NLM retired NIHSeniorHealth as web browsers had caught up to the needs of people with all abilities and provided many of the capabilities of NIHSeniorHealth for any web site. Innovative in 2003, the features and advantages of a website devoted to the needs of seniors were available to people who needed them through everyday tools; people could get the information from MedlinePlus in the manner of their choosing, whether reading in a particular font size or color or by browser assisted voice [21].

\subsection{Linking People to Health Services with Go Local}

As MedlinePlus evolved to meet user needs, people were requesting and seeking local health services, in addition to information about health conditions. People wanted to find everything from nearby support groups, health screening services, treatment centers and more. The first Go Local site to launch and connect to MedlinePlus was the pilot of NC Health Info, run by the University of North Carolina at Chapel Hill (UNC-CH) Health Sciences Library [22]. Dr. Lindberg favored the model of working with a capable and progressive partner like the UNC-CH health sciences library and library school to create a working pilot and to use the lessons learned to inform later successes. He attended the launch event of the pilot at the public library in Pittsboro, NC in January 2004 along with U.S. Rep. David Price, several North Carolina state legislators and the state health officer, Leah Devlin.

Even while developing and piloting the system with UNC, NLM staff were simultaneously working with the next site, Missouri. Go Local Missouri was released later that year following an event at the University of Missouri, Columbia. Except for a few sites who chose to maintain their own software system, NLM hosted the Go Local software to ensure consistency in linking to MedlinePlus and to provide the system infrastructure at no cost to each Go Local project. As time went on, more and more organizations committed to create and maintain a Go Local site with a total of 34 projects in 30 states and the District of Columbia, that provided coverage for 46 percent of the US population by 2009. That year, NLM was given an NIH evaluation award to study the effectiveness of the Go Local program. 
The evaluation of use data, interviews and other feedback concluded that while the contributing partners were dedicated to the mission of providing health services connections, the overall program wasn't sustainable for the long term and there were viable and more prominent ways for people to get health services information. As NLM summarized in 2010, "In today's Internet environment, there are many comparable resources to an Internet health services directory such as Go Local. Internet search engines that people use daily, such as Google, Yahoo, and Bing, bring a wide range of health services listings to users, and many offer added value that Go Local cannot. These sites list provider-level directory information and can collect user reviews. Today's health insurance sites give insured users local practice details, such as hours, languages, fees, and quality ratings based on provider or facility performance measures that would require too much labor-intensive manual collection for Go Local to provide, but that our users have said they want in a health services site." [23]

During his tenure, Dr. Lindberg often demonstrated the importance of ceremony and hospitality in recognizing contributions and honoring colleagues. At the close of the Go Local program, he supported and spoke at a reception for all the Go Local partners at the 2010 Annual Meeting of the Medical Library Association, in Washington D.C. He and other library leaders acknowledged the shared goals in starting the program and the reality of the time to end it. One of the partners, M.J. Toohey, Associate VP at the Maryland Health Sciences and Human Services Library, highlighted that for her library, one of the most positive outcomes of Go Local was the goodwill, recognition, and new partnerships they developed at their institutions, in their community and state. Other Go Local leaders echoed this theme that being part of Go Local had strengthened important community connections.

\subsection{Connecting from Patient Portals of Electronic Health Records}

As EHRs became more common and were incentivized by the U.S. government's meaningful use program, the staff of MedlinePlus moved to leverage MedlinePlus's highly organized corpus of consumer health information to be delivered to patients through patient portals. By leveraging the UMLS and its clinical vocabularies and mapping health topics to terms used in EHR systems, patients could directly link to MedlinePlus information on tests, drugs and conditions. The success of this effort resulted from an initial pilot with highly competent and motivated partners, in this case, the Institute for Family Health in New York, their Director, Neil Calman M.D., and their EHR provider, Epic Systems. With the support of Dr. Lindberg, NLM worked closely with the Institute for Family Health to create systemic connections so that a patient in Epic's MyChart could quickly find information related to any problem mentioned in their record. Called MedlinePlus Connect, this program was recognized in 2011 with a HHS Innovates award and continues to use web and medical terminology standards to provide this service today to many health organizations via many EHR products and other systems.

\section{Lasting Legacy in NLM's Consumer Health Services}

During his long tenure, MedlinePlus and its related products served to further Dr. Lindberg's vision of reaching patients with quality information, not just in text, but with sound, images, animations, and in their own language, whether simplified English, Spanish or another language. As he had hoped, MedlinePlus connected to and integrated 
with other NLM resources, including PubMed, ClinicalTrials.gov, Genetics Home Reference, and others, often using the results of NLM research and development to accomplish this integration.

The consumer information program also followed his vision of piloting and experimenting with new ways to reach people. Staff worked to continually evaluate the effectiveness of functions and services, keeping what worked, such as Connect, and ending programs that were inefficient to effectively maintain, were supplanted by new technology, or where patients and their families were better served by other NLM or outside services. By 2014, more than 400 million visitors viewed over one billion pages of information on MedlinePlus, making it a leading resource for people the world over. Dr. Lindberg's view that patients want to learn about their health for themselves, learned from his early experiences, remains true today.

\section{References}

[1] National Library of Medicine. Swearing-in ceremony: Donald A.B. Lindberg, M.D., Director, National Library of Medicine, October 11, 1984 [Internet] [cited 2021 July 8] Available from: http://resource.nlm.nih.gov/101629547.

[2] National Library of Medicine Board of Regents. Minutes of Board of Regents Meeting. September 1998 [Internet]. [ cited 2021 March 23] p. 6-8. Available from: https://www.nlm.nih.gov/hmd/manuscripts/nlmarchives/bor/Sept1998.pdf

[3] Wood FB, Lyon B, Schell MB, Kitendaugh P, Cid VH, Siegel ER. Public library consumer health information pilot project: results of a National Library of Medicine evaluation. Bull Med Libr Assoc. 2000 Oct;88(4):314-22. PMID: 11055298; PMCID: PMC35252.

[4] National Library of Medicine. Public Library Initiative/New Consumer Health Site [Internet] 1998 Oct 22 [cited $2021 \quad$ Mar 23] Available from: https://wayback.archiveit.org/5418/20160227222448/https://www.nlm.nih.gov/archive/20040831/news/press_releases/medplus .html

[5] National Library of Medicine Board of Regents. Minutes of the Board of Regents Meeting May 1999. Attachment 1 NLM and health information for the public [Internet][cited 2021 March 25] Available from: https://www.nlm.nih.gov/od/bor/bor599.html

[6] National Library of Medicine Board of Regents. Long Range Plan 2000-2005 [Internet]. Bethesda (MD): US Department of Health and Human Services, Public Health Service, National Institutes of Health; 2000 [cited 2021 March 25] Available from: http://resource.nlm.nih.gov/100963683. p. 6.

[7] Ahmed T. MedlinePlus at 21: a website devoted to consumer health information. Stud Health Technol Inform. 2020 Jun 25;269:303-312. DOI: 10.3233/SHTI200045. PMID: 32594005.

[8] Miller N, Lacroix EM, Backus JE. MEDLINEplus: building and maintaining the National Library of Medicine's consumer health web service. Bull Med Libr Assoc. 2000 Jan;88(1):11-7. PMID: 10658959; PMCID: PMC35193.

[9] National Library of Medicine. Programs and services Fiscal Year 2000 [Internet] [cited 2021 June 2] Available from: https://www.nlm.nih.gov/ocpl/anreports/fy2000.pdf

[10] Landro L. Health web sites get better at explaining complex medical data. The Wall Street Journal. Section B, Cover. 2000 Jul 14.

[11] Landro L. The federal government is using the Web to open up a treasure trove of medical information to consumers. The Wall Street Journal. 2001 Feb 21:R8,R12.

[12] Consumer Reports Online. How to research a medical topic online. 2000 [Accessed 2015 Nov 15] http://consumerreports.org/special/samples/reports/0009med0.htm. No longer available.

[13] National Institutes of Health. MEDLINEplus counts on input, insights from NIH Advisors. NIH Record 2003; June 10 LV(12):9

[14] MedlinePlus [Internet]. Bethesda (MD):National Library of Medicine (US) Public Services Division. 2000 [cited 2021 Jun 2] Available from: https://wayback.archive-it.org/org350/20170228070908/https://medlineplus.gov/milestones.html

[15] National Library of Medicine. Programs and services Fiscal Year 2001 [cited 2021 June 2] Available from: https://www.nlm.nih.gov/ocpl/anreports/fy2000.pdf p. 14 
[16] Voge S. NOAH--New York Online Access to Health: library collaboration for bilingual consumer health information on the Internet. Bull Med Libr Assoc 1998 Jul;86(3):326-34. PMID: 9681167 PMCID: PMC226378

[17] National Library of Medicine. MedlinePlus goes Spanish. [Internet] 2002 Sep 9 [Cited 2021 Jun 2] Available from: https://www.nlm.nih.gov/archive/20040831/news/press_releases/medplusspanish.htm

[18] National Library of Medicine Strategic Plan for Addressing Health Disparities 2004-2008. 2004 [Internet] [Cited 2021 Jun 2]. Available from: https://www.nlm.nih.gov/pubs/plan/nlm_health_disp_2004_2008.html\#_Toc77065245

[19] VisualDx. Skinsight. Rochester, NY [Internet] [C̄ited 2021 Jun 3]. Available from: http://www.skinsight.com/skin-conditions/child/rubeola-measles?Imiw9cApl

[20] National Institutes of Health. NIH launches NIHSeniorHealth.gov. [Internet] 2003 Oct 14 [Cited 2021 Jun 3]. Available from: https://www.nlm.nih.gov/archive/20120510/news/press_releases/nihseniorhealthpr03.html

[21] Dine B, Dailey S. NIHSeniorHealth.gov to be retired in August 2017. NLM Tech Bull 2017 MayJun;(416):e5 https://www.nlm.nih.gov/pubs/techbull/mj17/mj17_nihseniorhealth_retirement.html

[22] Hilligoss B, Silbajoris C. MedlinePlus goes local in NC. Journal of Consumer Health on the Internet 2004 Oct;8(4), 9-26, DOI: 10.1300/J381v08n04_02 Available from: https://doi.org/10.1300/J381v08n04_02

[23] Klein L. NLM to discontinue support of MedlinePlus Go Local. [Internet] NLM Tech Bull 2010 MarApr;(373):e18. Available

from: https://www.nlm.nih.gov/pubs/techbull/ma10/ma10_go_local_discontinue.html 